Paes de Carvalho, Fernando.

Director, Escuela de Bellas Artes de la Universidad de Puerto Rico - UPR,

Alumno, doctorado, Facultat de Belles Arts de Sant Carles, UPV.

\title{
La pintura como el registro de los vestigios de un acontecimiento.
}

\author{
TIPO DE TRABAJO
}

Comunicación.

PALABRAS CLAVE

Pintura, ausencia, marcas, ruinas, vestigios.

KEY WORDS

Painting, absence, marks, ruins, trace.

RESUMEN

En el presente trabajo, propongo aproximarnos a la pintura desde la perspectiva de la no pintura, donde se cuestiona el objeto pictórico representacional, al utilizar conceptos como ausencia, marca y ruina. Por ello, propongo una incursión a una realidad invisible en la pintura que, a partir de sus marcas y fragmentos, me permite una mirada arqueológica al medio. Ese diálogo con lo ausente, lo invisible, a través de su rastro, tiene su origen en el concepto de Spur, de Walter Benjamin. Desde luego, es interesante observar la relación de Spur con el tiempo. El tiempo, en su dictadura implacable, nos empuja constantemente hacia la desaparición, hacia la disolución de la materia orgánica y hacia la pérdida de identidad. Ante este hecho, solo nos resta observar los rastros dejados, y las pistas de una eventual presencia. Por lo que el trabajo propuesto refleja las observaciones hechas a un lugar en específico, el taller (salón) de pintura ubicado en la Escuela de Bellas Artes de la Universidad de Puerto Rico, donde me desempeño como profesor y director. Se observa el constante vaivén de alumnos cada ciclo académico, durante dos décadas de enseñanzas. La observación, específicamente, se refieren a la acumulación de restos de materiales diversos de pintura sobre las superficies a través de los años, y que constituye, a partir de la investigación, el terreno a ser excavado y estratificado, buscando diferencias entre lo visto (descubierto) y lo que permanece ausente. Ir a fondo, retirar las capas, desvelar, archivar son, en esencia, la metáfora de la rememoración benjaminiana. De este modo, el espacio del salón ha sido habitado, como propone Benjamin, en el sentido de crear hábitos. Un lugar estratificado es un lugar habitado por el tiempo. Temas como pintura, vacío, azar, sombra y huella serán abordados en este ensayo.

\section{ABSTRACT}

In this paper, I propose to approach painting from the perspective of non-painting, where the representational pictorial object is questioned by using concepts such as absence, mark and ruin. Therefore, I propose an incursion on an invisible reality in painting, that from its marks and fragments, it will allow me an archaeological look of its medium. This dialogue with the absent, the invisible, through its trail, stems from the concept of Spur, by Walter Benjamin. Of course, it is interesting to note the relationship of Spur and time, time, in its relentless dictatorship, constantly pushing us towards the disappearance, toward the dissolution of organic matter and the loss of identity. Given this fact, it only remains for us to observe the traces left, and the tracks of an eventual presence. So the proposed work reflects observations made of a specific location, the painting studio located in the Department of Fine Arts at the Faculty of Humanities in the University of Puerto Rico, where I work as a professor and director. The constant swaying of students each academic year, during two decades of lessons is observed. Observation specifically refers to the accumulation of debris of various paint materials on the workshop surfaces throughout the years, which constitutes, from the research, the ground to be excavated and delaminated looking for differences between what is seen (discovered) and what remains absent. Excavating thoroughly, removing layers, unveiling, archiving are essentially the metaphors of Benjamin's remembrance. In this way, living space has been inhabited, as Benjamin suggests, in the sense of creating habits. A stratified place is a place inhabited by time. Topics such as paint, absence, chance and trace will be addressed in this essay. 


\title{
CONTENIDO
}

\author{
“ - No veo nada, señor (Holmes) \\ - Al contrario Watson, lo tiene todo a la vista. Pero no es capaz de razonar a partir de lo que ve". (Doyle, 1892, p. 4) ${ }^{\mathrm{i}}$
}

Walter Benjamin, en uno de sus muchos sueños, se encontraba frente a un inmenso muro. Estaba a unos pocos centímetros de distancia, lo que no le permitía ver la dimensión del muro o su entorno y menos su identidad o localización, pero poco a poco percibió que estaba frente al muro de la catedral de Notre Dame en París. A pesar de encontrarse de frente a la catedral, no podía verla. "Su angustia crecía a medida que reconocía de memoria el lugar, pero estaba paralizado, ciego, imposibilitado de ver toda su dimensión, toda su belleza: una pesadilla". (Duarte, 2011, p. 137)

Si visualizamos los salones vacíos de una escuela de arte, las aulas de pintura, en específico, se hace imposible retener, en una imagen, toda la dinámica, las experiencias compartidas y la energía desprendida en hacer el arte. Estamos asimilados culturalmente a dirigir la mirada a lo que se produce, al producto, a lo visible y a lo grande; y no miramos a cómo se produce, al proceso, a los vestigios, a lo pequeño. Preferimos el brillo al polvo, el material nuevo y listo al inacabado, inconcluso. Nuestros ojos buscan el cuadro terminado, listo para exhibirse. Por lo que nuestras miradas se ciegan ante la limpieza superficial de las primeras impresiones. Y lo visible inmediato, muchas veces, no revelan los imperfectos, los espacios en blanco, lo minúsculo.

Según Derrida: "Desde el eidón platónico hasta el objeto o la objetividad moderna, la filosofía occidental puede ser leída como una historia de la visibilidad, de la interpretación de lo visible". ii

Si bien es cierto que lo invisible trabaja desde lo visible, haciendo "una contrapartida secreta", como lo establece Merleau-Ponty (2010, p. 184), lo anterior pone en manifiesto toda la reflexión generada a partir de la idea del vacío; vacío existencial, vacío material, a partir de la ausencia de un referente visual, de una presencia sólida en el aire.

Aun suponiendo que veamos objetos visibles y sólidos, no significa que las imágenes que se generan corresponden a los objetos vistos, tal como indica Bertrand Rusell: "Decir que veo una estrella porque veo la luz que procede de ella es como decir que estoy viendo Australia cuando veo a un australiano". iii

Por lo que lo invisible se revela a través del rastro incorporado al objeto, que en el caso que nos ocupa a partir de ahora, tal objeto es el cuadro pictórico o la pintura misma en cuanto a un conjunto de significaciones correspondientes a un lenguaje de un medio artístico en específico.

Es decir, la pintura es un arte o medio cuyo lenguaje ha sido exhaustivamente determinado desde el famoso texto de Alberti, Della pictura, donde nos enumera y clasifica sus componentes: circumscriptione, compositione, receptione di lumi. Sin embargo, su existencia ha sido cuestionada durante todo el siglo XX hasta la actualidad, puesto que su tradición ha sido varias veces desconstruida, principalmente en las últimas décadas, transformándose y redefiniéndose en otros medios como la fotografía, instalación, happening, performance, vídeo, entre otros. Por lo tanto, los lenguajes artísticos establecidos a partir de la segunda mitad del siglo XX han mantenido una relación ambivalente con la tradición de la pintura: a la misma vez que la rechazan como medio contemporáneo, de ella heredaron discursos y posibilidades para la construcción y desarrollo de sus propios medios.

Querer pensar la pintura es, por lo tanto, una tarea compleja. Diversas cuestiones vienen a flote: ¿Cómo se define ese algo pictórico? ¿Cómo es la cosa de la pintura más allá del cuadro, del marco? ¿Cuáles son los sentidos posibles de la pintura en el contexto del arte contemporáneo? ¿De qué trata ese lenguaje hoy día? ¿Cuáles son sus elementos visibles e invisibles?

Según Rosalind Krauss, la ampliación de un campo nos lleva a dos aspectos implícitos del mismo proceso de ampliar. El primero de estos se refiere a la práctica de incorporar otras tecnologías o medios o lenguajes. El segundo aspecto indica que después de la posmodernidad, la práctica artística ya no está definida con relación a elementos formales o físicos de un determinado medio y sí con relación a las "operaciones conceptuales y lógicas dentro de un conjunto de definiciones culturales, por lo cual varios medios, técnicas o lenguajes pueden ser utilizados en la construcción de una poética" (Krauss, 1988, pp. 87-94). Lo que percibimos es que, en el caso de la pintura, ésta ofrece un variado y ampliado conjunto de posibilidades que el artista puede explorar. Es decir, ofrece una gama de posibilidades a partir de las condiciones dadas por las mismas definiciones tradicionales del medio y su larga historia. 


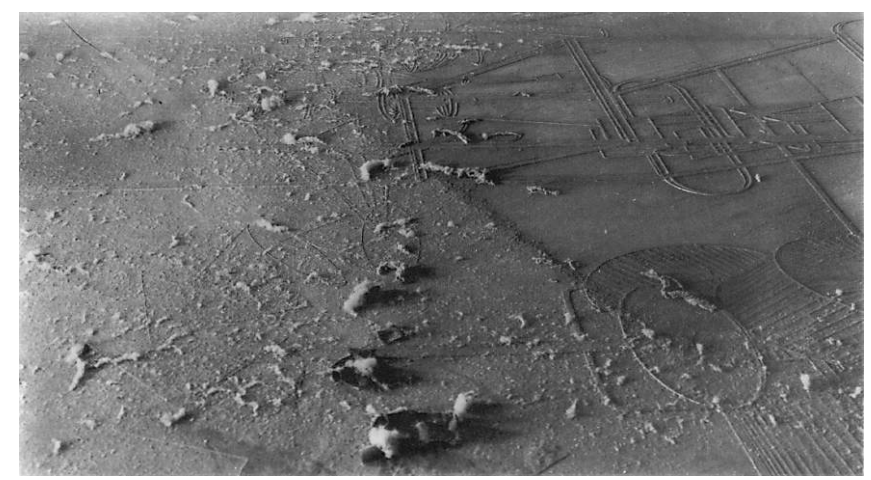

Figura 1- Élevage de poussière (Criadero de polvo). Man Ray. Fotografía. 1920

Lo anterior, en la dialéctica entre presencia y ausencia, algunos pintores han preferido eliminar a añadir, pintar lo invisible a representar el objeto visible, proponiendo una representación que se escapa al objeto pintado, al cuadro enmarcado.

Es el caso de la obra Criadero de polvo (1920) de Man Ray, registro fotografico de la acumulación de polvo sobre el Gran Vidrio de Marcel Duchamp. Ese color original que busca establecer Duchamp con la presencia del polvo sobre el Gran Vidrio, solo es perceptible después de varios meses de exposición. Así, no es posible observar con el ojo desnudo las primeras capas de ese registro del tiempo a través de su pigmentación natural, de su exposición al azar. Para Yve-Alain Bois (1997, p. 226), "el polvo es, semióticamente hablando, un índice", una inscripción del tiempo y un rastro, una pista de un acontecimiento. Cuando se acumula en capas, el polvo adquiere diferentes espesores, transparencias y duración. Duchamp había conceptualizado la pintura con la presencia del polvo como un ingrediente no-cromático de la composición.

"Para los tamices, en el vidrio, dejar que se deposite el polvo sobre esta parte, un polvo de 3 ó 4 meses y limpiar bien alrededor, de modo que este polvo sea una especie de color" (Duchamp, En: Ramírez, 2006, p. 105).

Ahora bien, ¿puede una cosa hacerse representar por otra sin perder su presencia efectiva, ya que para hacerse presente debe ausentarse de lo que la representa? Para este ensayo, lo que realmente se implica en una obra de arte es la conexión con lo ausente, ya sea esa ausencia, el devenir o la memoria.

Así, una forma puede representar otra, cuya existencia y significado parece querer permanecer implícito. Para la deconstrucción, "una pintura no es otra cosa que el espacio de representación donde los diversos sistemas que lo constituye se vuelven implícitos". (Martin, 1999, p. 70)

En el caso de Claudio Parmiggiani, nos expone esa implícita ausencia a través de una serie de pinturas soplando polvo y humo sobre objetos que luego son retirados, indicando su presencia en sombras. La fantasmagoría proporcionada por el rastro del objeto, difuminadas en la superficie plana de la madera, confiere ese aspecto de gris psíquico a que se refiere Didi-Huberman con su texto Grisalla (2014).

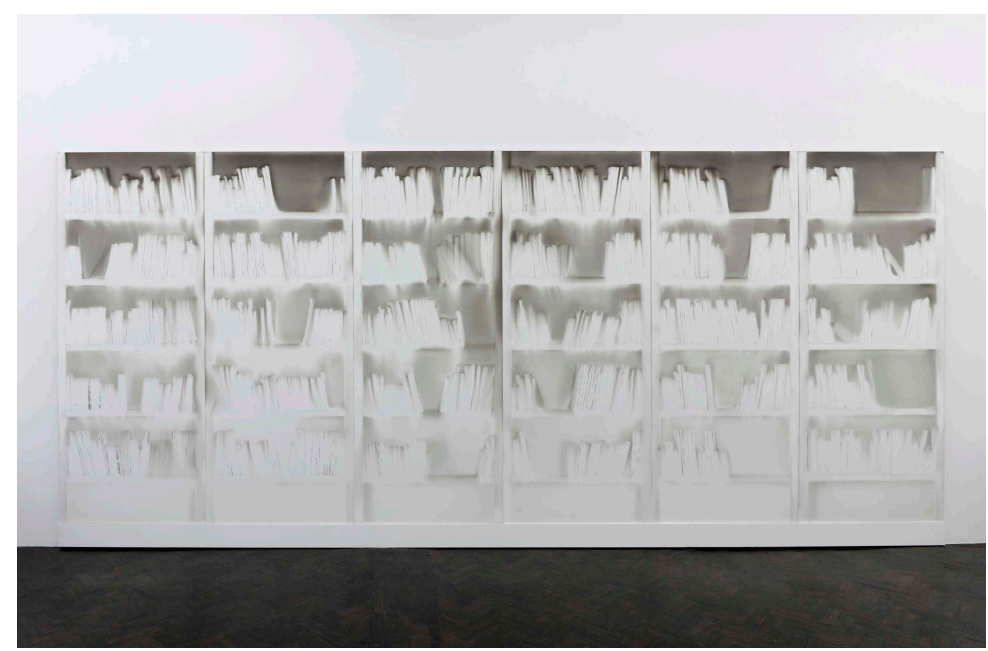

Figura 2 - Claudio Parmiggiani Untitled. 2008.

De esta forma, al analizar cómo es la pintura y no el objeto en sí, estamos analizando los fenómenos que agrupan su acontecer, ubicando el sentido en una no-mirada-invisible, en un espacio-otro. 
Desde luego, se nos hace interesante observar que el tiempo, en su dictadura implacable, nos empuja constantemente hacia la desaparición, y hacia la disolución de la materia orgánica, por lo tanto, hacia la pérdida de identidad. Ante este hecho, solo nos resta observar los rastros dejados por el tiempo, ya que, al hacerlo, nos permite aproximarnos a una idea de permanencia o de registro ante el inevitable fenómeno de la muerte.

Acercándonos al pensamiento de Walter Benjamin (2010), pretendemos establecer al principio, que el rastro o Spur, es la aparición de una proximidad.

De esta manera, los fragmentos y restos encontrados rememoran un pasado o experiencia vivida a través de una reconstrucción. Para Benjamin (2010), los vestigios y restos son una forma de apoderarse de lo vivido anteriormente de manera que:

\begin{abstract}
"La memoria no es un instrumento para conocer el pasado, sino sólo su medio. La memoria es el medio de lo vivido, al igual que la tierra viene a ser el medio en que las viejas ciudades están sepultadas. Y cualquiera que quiera acercarse a su pasado tiene que comportarse como un hombre que excava. Y, sobre todo, no ha de tener reparo en volver una y otra vez al mismo asunto, en irlo revolviendo y esparciendo tal como se resuelve y esparce la tierra" (Benjamin, 2010, p. 350).
\end{abstract}

En este sentido, el trabajo que pretendo exponer aquí se centra en un espacio físico determinado. Específicamente, se tomará como foco de análisis un salón de clases de pintura ubicado en la Escuela de Bellas Artes de la Universidad de Puerto Rico, donde me desempeño como profesor y director.

De este modo, el trabajo refleja las observaciones hechas al espacio del salón, durante dos décadas de enseñanza, ante el constante vaivén de alumnos y clases en cada semestre académico. Se establece un ritmo, y se observan las marcas de ese movimiento, se observa el espacio vacío.

La experiencia de estar presente en el lugar por tanto tiempo, mezclada con la experiencia de aquellos que frecuentaron el lugar, permean la membrana fina de la invisibilidad entre lo vivido y la memoria exponencial de las sensaciones compartidas, de las dinámicas de grupo, de las energías desprendidas y del registro de estas experiencias a través del rastro y de vestigios minúsculos que permanecen ante el tiempo, en el aire, el polvo, y que son fragmentos de un acontecer. Pequeñas piezas que utilizaremos para componer el todo, aunque es todo siempre será incompleto, siempre inconcluso.

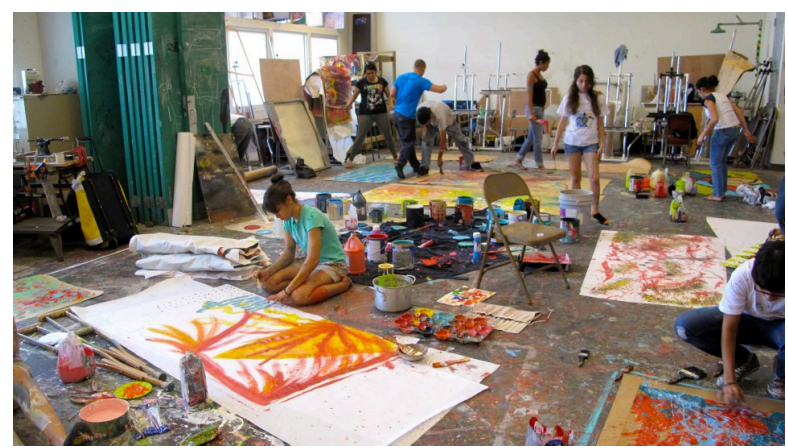

Figura 3 - Salón de pintura.

De esta forma, este trabajo pretende revalorizar la memoria del lugar y de registrar momentos, a partir del fragmento, del sobrante material de cientos de individuos que frecuentaron el espacio y dejaron sus restos y sus rastros pictóricos en el piso, en las mesas, de forma inconsciente, pero que forman una escritura ciega, una historia desconstruida, y son el espejo (speculum) de un proceso nolineal de enseñanza-aprendizaje. Así, el piso, mesas, superficies del lugar han sido pobladas por diferentes capas de materiales pictóricos, en diferentes tiempos y contextos particulares.

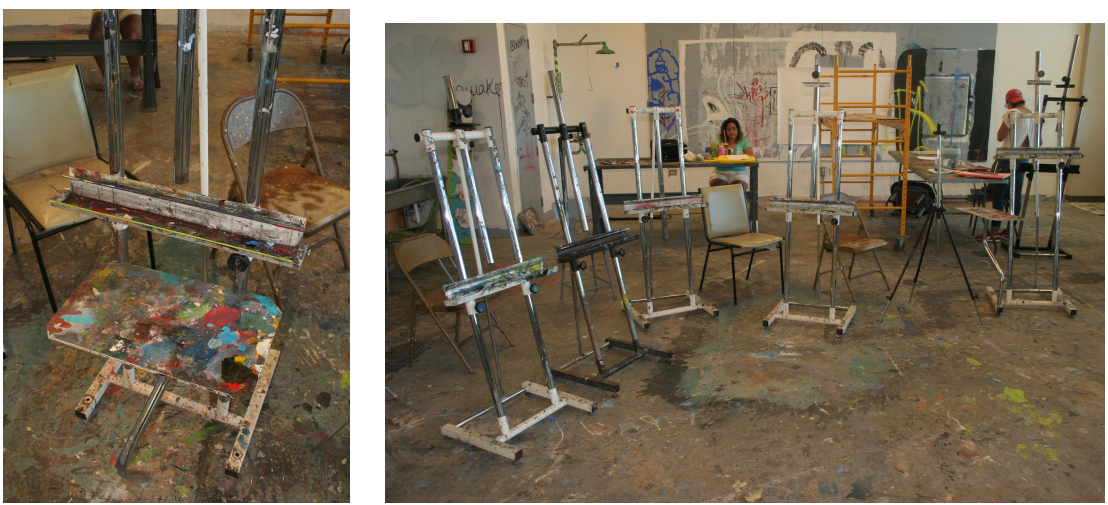

Figura 5 - Salón de Pintura, (detalle caballete, al lado) 
El trabajo trata de recuperar, registrar, seleccionar, presentar la acumulación de los restos materiales en "pieles" de pintura que serán transferidos a otro soporte.

El trabajo se trata, pues, de una rememoración (eigedenken); pero esa rememoración, siguiendo el pensamiento benjaminiano, es de carácter diferente al de una memoria linear y temporal, puesto que obliga todo a ser reconstruido y resinificado en el tiempo presente, en el "aquí y ahora".

Aunque, ese tiempo presente, para Derrida (2010) es también tan sólo un concepto, ya que lo único que existe es el trazo, un puente entre la memoria y la idea de futuro. Y aquí consiste la diferencia entre presencia y presente.

Para Derrida (2010), solo existe la presencia y la ausencia. Presencia en el sentido de que elaboramos actos que sólo podrán ser repetidos en el futuro, utilizando la memoria de un pasado hecho presencia. Ausencia en el sentido de que la memoria puede avivar imágenes del pasado, pero jamás puede resucitarlo, jamás puede vivirlo nuevamente.

En este sentido, "lo importante para el que rememora, no es lo vivido, sino el tejido de su rememoración" (Benjamin, 1994, p.37). Es decir, al tratar de buscar objetos que están ocultos, rehacer imágenes que ya no están presentes y de reconstruir una historia a partir del fragmento y del reflejo.

De esta forma se establece, como lo indica Foucault (1979), un proceso arqueológico. Así, una de las premisas de este trabajo es ejercer el método de estratificación benjaminiano. Ir a fondo, retirar las capas, seleccionar, descubrir, desvelar, registrar, archivar, son, en esencia, la metáfora de la rememoración.
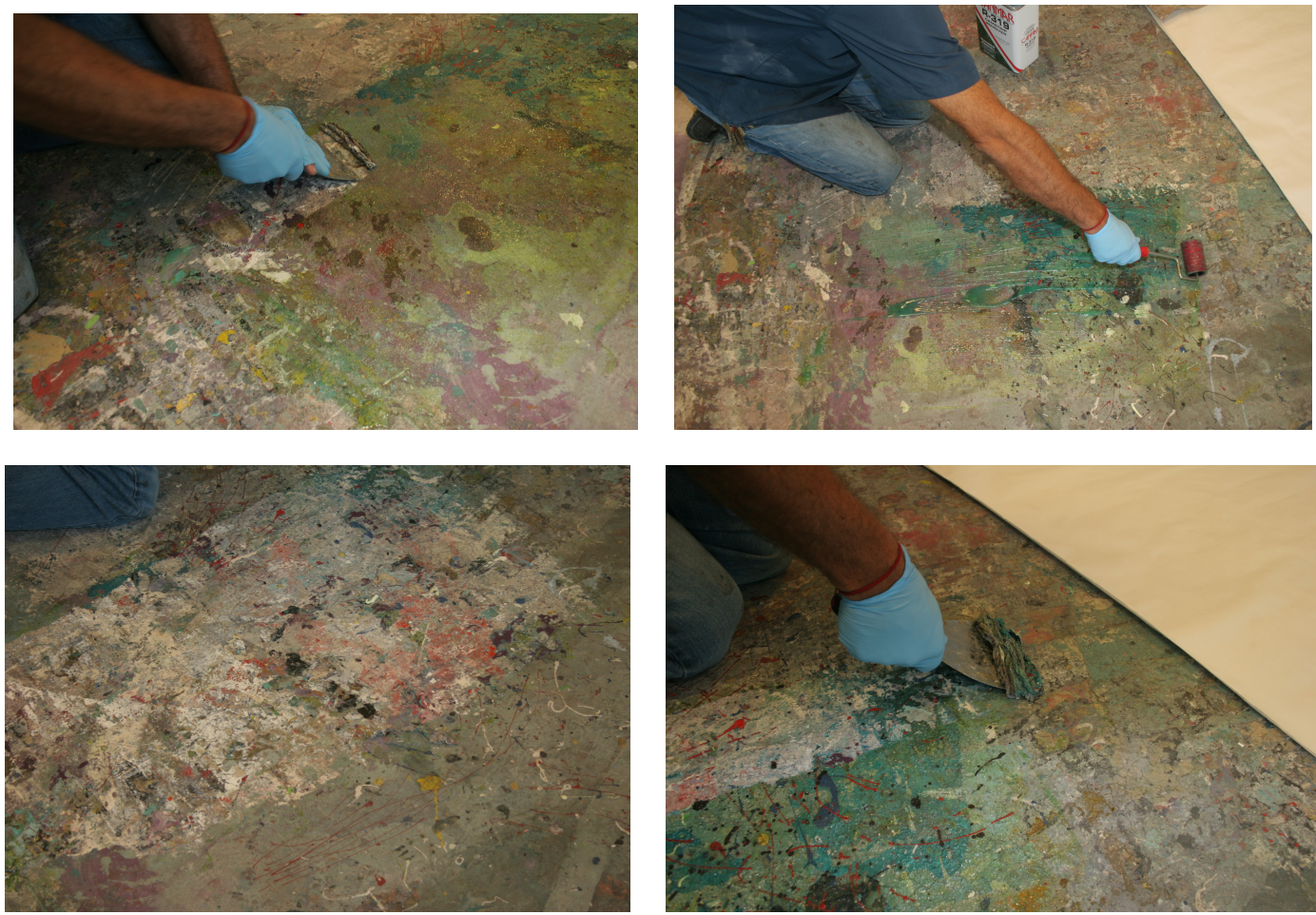

Figure 4 - Proceso de raspar la superficie y de retirar las capas de pintura.

Al aplicar el acido a la superficie y se deprenden los restos de pintura en capas, revelando otras, de diferentes tiempos. Cada fragmento revela un pedazo de la memoria perdida, dispuesta a ser rememorada. Y con ello se vuelven visibles las marcas e historias invisibles de las personas que frecuentaron el espacio, a través de sus rastros.

Para Benjamin, un lugar estratificado es un lugar habitado por el tiempo, pero por un tiempo discontinuo: un presente-pasado. En conclusión, la piel (tejido) de esta rememoración se hace visible a través de la piel levantada de las superficies del lugar estratificado.

A seguir, algunos ejemplos del trabajo. 




Figura 5 - Detalle de las capas desprendidas del piso.

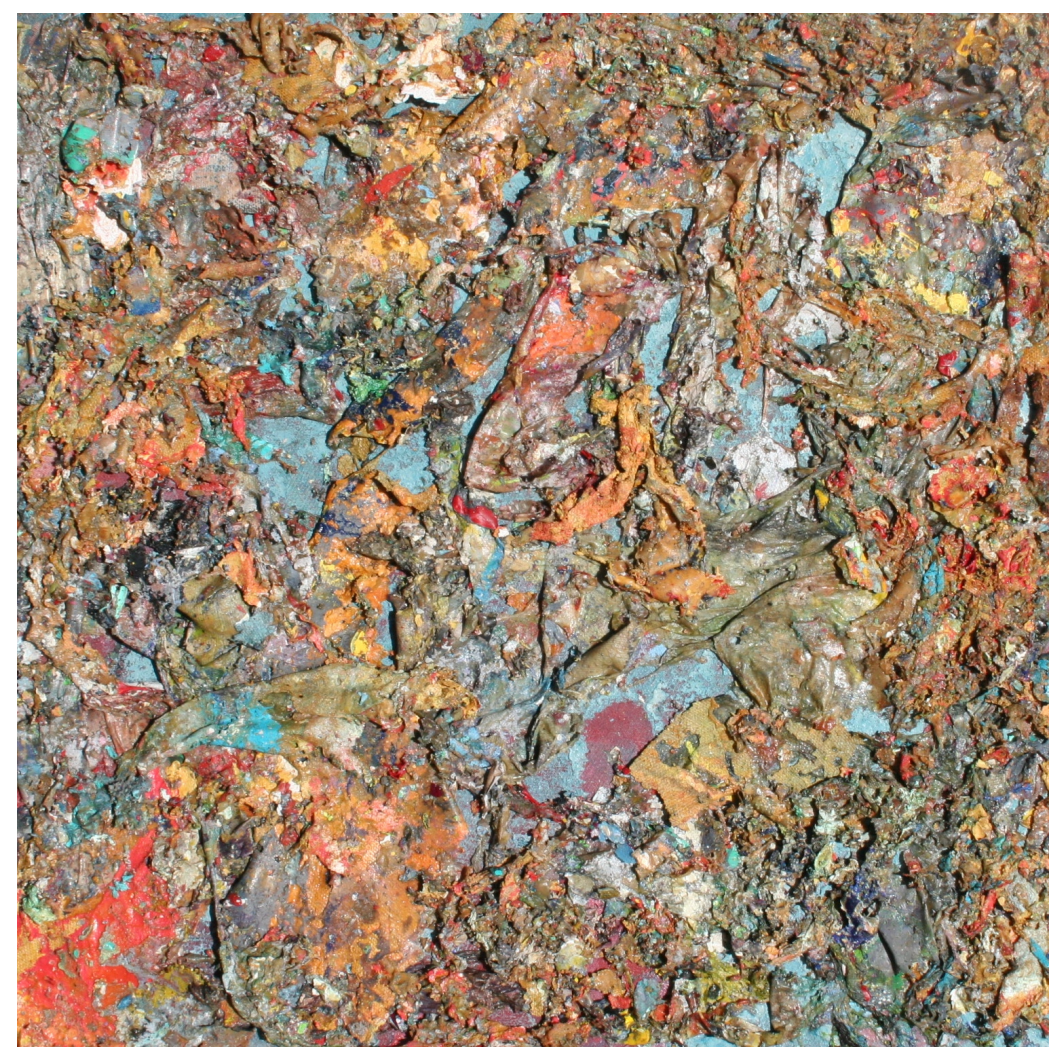

Figura 6- Acumulaciones 1. Materiales diversos de pintura sobre PVC. 43 X 43 cm. 2015. 


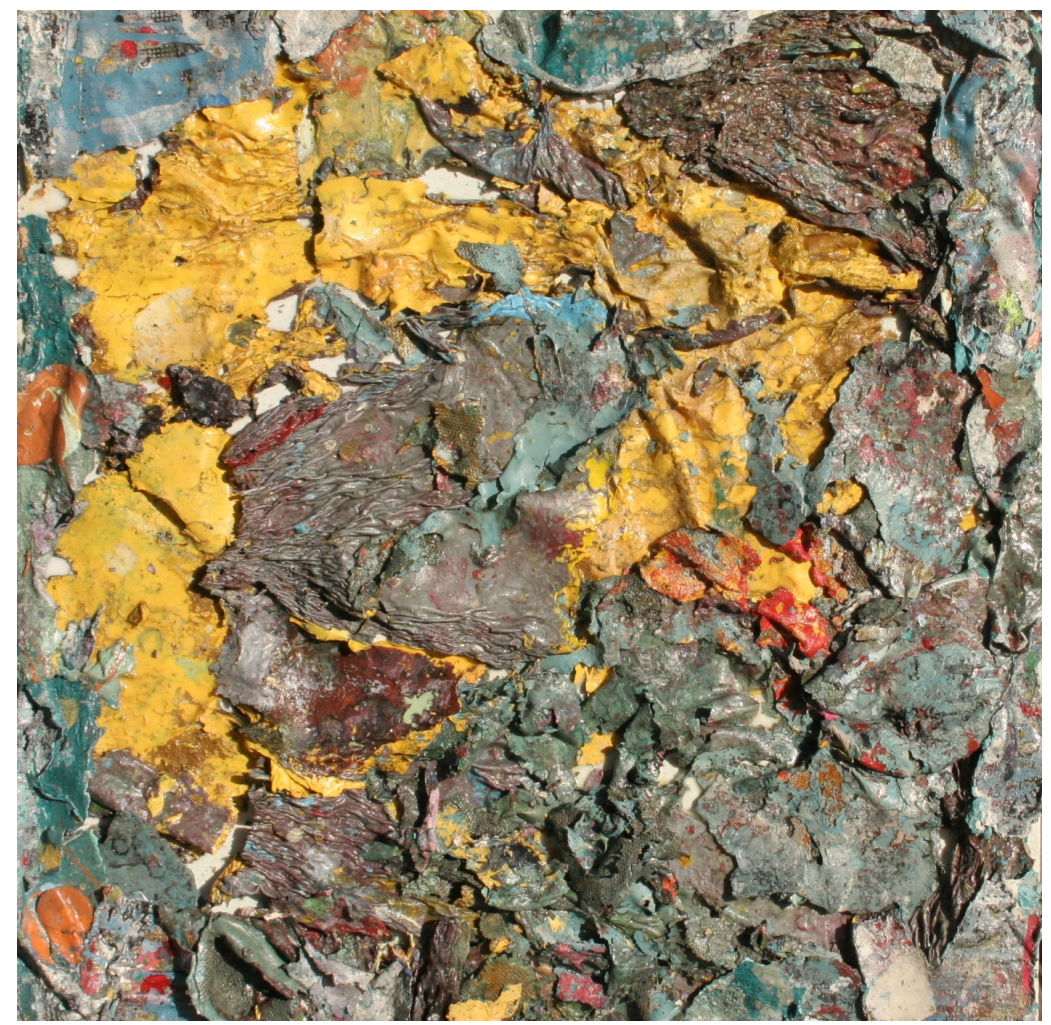

Figura 7 - Acumulaciones 2. Materiales diversos de pintura sobre PVC. 43 X $43 \mathrm{~cm} .2015$.

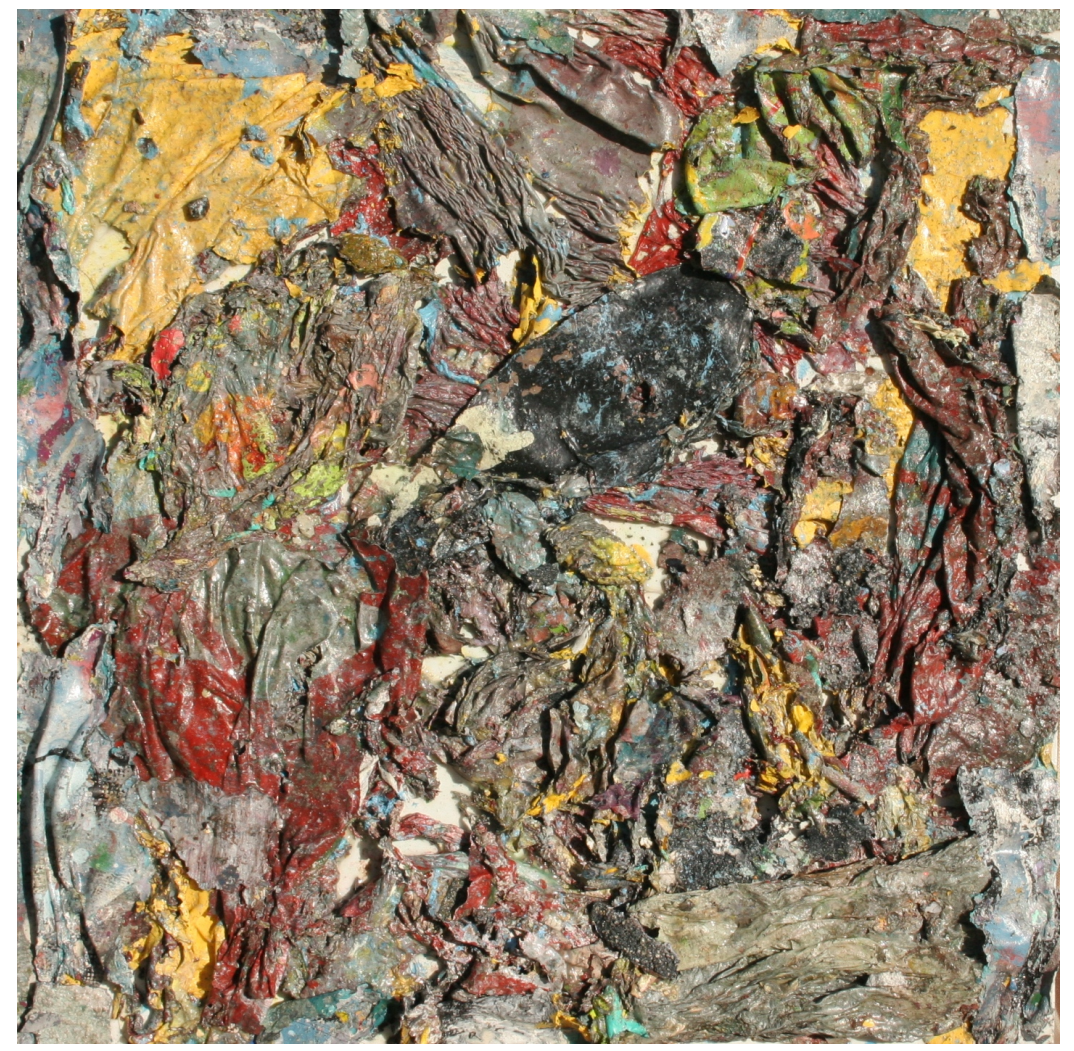

Figura 8 - Acumulaciones 3. Materiales diversos de pintura sobre PVC. 43 X $43 \mathrm{~cm} .2015$. 


\section{FUENTES REFERENCIALES.}

- BENJAMIN, Walter. Experiencia e pobreza. En: Magia e técnica, arte e política: ensaios sobre literature e história da cultura. Ed. Brasiliense. São Paulo. 1994.

- BENJAMIN, Walter. Alas constelaciones. Círculo de Bellas Artes. Madrid. 2010.

- BOIS, Yve-Alain; KRAUSS, Rosalind. Formeless. A User's Guide. Zone Books. New York. 1997.

- DERRIDA, Jacques. Memórias de Cego, O auto-retrato e outras ruínas, Fundação Calouste Gulbenkian. Lisboa. 2010.

- DIDI-HUBERMAN, George. Grisalha. Poeira e poder do tempo. Trad. R. P. Cabral. J. F. Figueira e V. Silva Editores. 2014.

- DUARTE, Paulo Sergio. Vergara. Automática Edições. Río de Janeiro. 2011.

- ENAUDEAU, Corinne. La paradoja de la representación. [En línea]. Escuela de Filosofía Universidad ARCIS. Chile. 1998. Disponible en Web: <http//www.philosophia.cl>. Visualizado en: [1/06/2015].

- FOULCAULT. Michel. La arqueología del saber. Trad. Aurelio Garzón del Camino. Siglo XXI. México. 1979.

- KRAUSS, Rosalind. La originalidad de la vanguardia y otros mitos modernos. Alianza. Madrid. 1988.

- MARTIN, Louis. Le discours de la figure, Études sémiologiques: écritures, peinture. En: Uma cartografia transtornada. A Guernica de Carlos de Oliveira. José Paulo Pereira. Angelus Novus. Braga. 1999.

- MERLEAU-PONTY, Maurice . Lo visible y lo invisible. Nueva Visión. Buenos Aires. 2010.

- RAMIREZ, Juan Antonio. Duchamp. El amor y la muerte, incluso. Siruella. Madrid. 2006.

\section{NOTAS}

'DOYLE, Sri Arthur Conan. El carbunclo azul. [En línea]. Disponible en Web: <http://holmes.materialdescargable.com/novelas/es_aventuras/El\%20Carbunclo\%20Azul.pdf> Enero de 1892, p. 4. Visualizado en: $[04 / 03 / 2015]$

ii DERRIDA, Jacques. El sacrificio. Trad. Cristóbal Durán. [En línea]. Disponible en Web: <http://www.egs.edu/faculty/jacquesderrida/articles/el-sacrificio/> . Visualizado en: [23/02/2015]

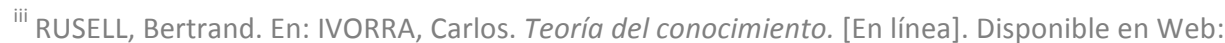
<http://www.uv.es/ivorra/Filosofia/TC/2.htm> . Visualizado en: [21/03/2015]. 